\title{
Critical role of plant biotechnology for the genetic improvement of food crops: perspectives for the next millennium
}

\author{
Rodomiro Ortiz \\ The Royal Veterinary and Agricultural University (KVL), Department of Agricultural Sciences, Plant Breeding and Crop Science Section, 40 \\ Thorvaldsensvej, DK-1871 Frederiksberg C, Copenhagen, Denmark. \\ Tel: +453528 3465 Fax: +453528 3468 \\ E-mail: ro@kvl.dk \\ http:// www.agsci.kvl.dk/breed
}

\begin{abstract}
This article reviews some of the highlights of modern plant biotechnology and discusses the potential applications of biotechnology in the betterment of farming systems in the next millennium. Plant biotechnology will facilitate the farming of crops with multiple durable resistance to pests and diseases, particularly in the absence of pesticides. Likewise, transgenes or marker-assisted selection may assist in the development of high yielding crops, which will be needed to feed the world and save land for the conservation of plant biodiversity in natural habitats. Hence, crops should be engineered to meet the demands and needs of consumers. The genetic base of crop production can be preserved and widen by an integration of biotechnology tools in conventional breeding. Similarly targeting specific genotypes to particular cropping systems may be facilitated by understanding specific gene-by-environment interaction(s) with the aid of molecular research. High quality crops with improved nutritional and health characteristics as well as other aspects of added-value may be obtained through multidisciplinary co-operation among plant breeders, biotechnologists, and other plant scientists. Co-ordinated efforts between consumers, policy makers, farmers and researchers will be required to convert the various aspects of a crop ideotype into components of new and improved farming systems of the next millennium.
\end{abstract}

The end of a year, decade, century, or, as now, of a millennium, always offers an opportunity to reflect on human activity in a particular discipline and to formulate a future strategy. Researchers constantly examine past occurrences in order to learn lessons that could help in the acquisition of new knowledge or for the further development of appropriate technology ensuing from it. Of course, science and technology are not isolated in the world, so researchers are expected to act according to the changing global society in which they live. This behaviour could be seen as the major challenge of crop biotechnology for the next millennium, i.e., to consider the social actors in the research agenda and work. In other words, market forces, user demands, and public views cannot be ignored when addressing basic and strategic research issues because these factors shape scientific investigations and technology or product development.

In writing this article the editor requested that I reflect on the critical role that plant biotechnology may have in assisting the genetic improvement of crops in the next millennium. Within this context, I will discuss somewhat philosophically, how biotechnology could help in solving the increasingly enormous challenge of our time: adequately and appropriately feeding the world in a sustainable manner.

This article restricts its discussion to gene-biotechnology, mostly developed in the past 20 years, and not other applications of non-gene biotechnology, which are known to humankind for many hundred years ago. In addition I prefer to "predict" the potential applications of biotechnology in the genetic enhancement of crops only within the period of the coming decade. It would be inappropriate to attempt to provide an outlook beyond this time-span because of the ever accelerating progress in this field. For example 15 years ago, plant biotechnology comprised only a few applications of tissue culture, recombinant DNA technology and monoclonal antibodies. Today, transformation, and marker-aided selection and breeding are just a few of the examples of the applications of biotechnology in crop improvement. This article was written through the eyes of a classical geneticist (having worked on the transmission of characteristics for the past 15 years), and the practical view of a conventional plant breeder, who has the desire to learn and accept innovative methods that enhance the available crop improvement techniques.

\section{Background information}

Writing about biotechnology for crop improvement in the next millennium does not appear to be an easy task owing to the rapid progress in this field. Within the last 100 years the world has seen the rise of genetics as a scientific discipline (1900s), the finding of DNA as the hereditary 
Ortiz, R.

material (1944), the elucidation of the double helix structure of the DNA molecule (1953), the cracking of the genetic code (1966), the ability to isolate genes (1973), and the application of DNA recombinant techniques (from 1980 onwards).

Methods of crop improvement have also changed dramatically throughout this century. Mass and pure line selection in landraces, consisting of genotype mixtures, were the popular breeding techniques until the 1930s for most crops. In the 1930s maize breeders started the commercial development of double cross hybrids that was followed by the extensive utilization of single crop hybrids since the 1960s (Troyer 1996). Pedigree-, bulk-, backcrossand other selection methods were also developed especially for self-pollinating crop species. Such scientific advances in plant breeding led to the so-called 'Green Revolution', one of the greatest achievements to feed the world in the years of the Cold War (Perkins 1997). Owing to this agricultural betterment, cereal production, which accounts for more than $50 \%$ of the total energy intake of the world's poor, kept in pace with the high average population growth rate of $1.8 \%$ since 1950 (Daily et al. 1998). Today, $370 \mathrm{~kg}$ of cereals per person are harvested as compared to only 275 $\mathrm{kg}$ in the 1950s; i.e., in excess of $33 \%$ per capita gain. Similar progress in other food crops resulted in $20 \%$ per capita gains since the early 1960s, according to FAO (1995). There are 150 million fewer hungry people in the world today than 40 years ago, though there are twice as many human beings. Despite this splendid progress in crop productivity, even greater progress must be made in order to feed an additional two billion people by the early part of the 21st century (Anderson 1996a). Around 800 million people are hungry today and another 185 million pre-school children are still malnourished owing to lack of food and water, or disease (Herdt 1998). Hence as suggested by the Nobel Peace Laureate, Norman Bourlag (1997), new biotechniques, in addition to conventional plant breeding, are needed to boost yields of the crops that feed the world.

Careful choice of such biotechniques as well as a realistic assessment of their potential in crop improvement are needed to avoid not only the criticism of the anti-science lobbyists but also the permanent distrust of pragmatic traditional breeders (Simmonds 1997). For example, a World Bank panel recently released for discussion a well based report concerning bioengineering of crops (Kendall et al. 1997). In this working paper, the panel members recommend "to give priority to all aspects of increasing agricultural productivity in the developing world while encouraging the necessary transition to sustainable methods". Indeed, plant biotechnology has been regarded as a priority area for technology transfer (Altman and Watanabe 1995), because genetically modified food, feed, and fibre are of vital concern to the developing world (Ives and Bedford 1998). Therefore, the rich industrialized world should share their biotechniques and avoid policies that do not allow the progress of agriculture in poor, nonindustrialized parts of the world (Erbisch and Maredia
1998), where this economic activity still provides 60 to $80 \%$ employment and $50 \%$ of national income (Anderson 1996a). Such support will assist the developing world towards food self-reliance (Herdt 1998), which will be very important to avoid hunger and keep peace in many regions of the tropics, where the agricultural sector remains the most important basis for economic growth. Furthermore, a wealthy society provides high living standards to its citizens.

Tissue culture was developed in the 1950s and became popular in the 1960s. Today, micropropagation and in vitro conservation are standard techniques in most important crops, especially those with vegetative propagation. At the beginning of the 1980s genetic engineering of plants remained a promise of the future, although gene transfer had already been achieved earlier in a bacterium. The first transgenic plant, a tobacco accession resistant to an antibiotic, was reported in 1983. Transgenic crops with herbicide, virus or insect resistance, delayed fruit ripening, male sterility, and new chemical composition have been released to the market in this decade (NCGR 1998; USDAAPHIS 1997). In 1996, there were about 3 million ha of transgenic crops grown in the world (mainly in North America) whereas in excess of 34 million ha (a 12-fold addition) of transgenic crops will be harvested this year in North America, Argentina, China, and South Africa among other countries. Argentina is the leading developing country with an excess of 4 million ha of transgenic herbicideresistant soybean. There are 4.4 million ha of transgenic corn (14\% of total acreage), 5 million ha of transgenic soybean (20\%), and 1.6 million ha of transgenic canola (42\%) grown only in North America (Moore 1998). It has been calculated that in 1998 US farmers are growing over $50 \%$ of their cotton fields with transgenic seeds, the largest percentage for any crop ever. Trees are the next target in the agenda of genetic engineering.

Allozymes were available as the first biochemical genetic markers in the 1960s. Population geneticists took advantage of such marker system for their early research. In the 1970s, restriction fragment length polymorphisms (RFLP) and Southern blotting were added to the tool box of the geneticists. Taq polymerase was found in the 1980s, and the polymerase chain reaction (PCR) developed shortly afterwards. Since then, marker-aided analysis based on PCR have become routine in plant genetic research and marker systems have shown their potential in plant breeding (Paterson 1996). Furthermore, new single nucleotide polymorphic markers based on high density DNA arrays, a technique known as 'gene chips' (Chee et al. 1996), have recently been developed. With 'gene chips', DNA belonging to thousand of genes can be arranged in small matrices (or chips) and probed with labeled cDNA from a tissue of choice. DNA chip technology uses microscopic arrays (or micro-arrays) of molecules immobilized on solid surfaces for biochemical analysis (Lemieux et al. 1998; Marshall and Hodgson 1998; Ramsay 1998). An electronic device connected to a computer may 
read this information, which will facilitate marker-assisted selection in crop breeding. In summary, since Mendel's work on peas, there have been five eras in genetic marker evolution (Liu 1997): morphology and cytology in early genetics (until late 1950s), protein and allozyme electrophoresis in the pre-recombinant DNA time (1960 mid1970s), RFLP and minisatellites in the pre-PCR age (mid 1970s - 1985), random amplified polymorphic DNA, microsatellites, expressed sequence tags, sequence tagged sites, and amplified fragment length polymorphism in the oligoscene period (1986 - 1995), and complete DNA sequences with known or unknown function as well as complete protein catalogs in the current computer robotic cyber genetics generation (1996 onwards) The driving force for such a development has been the scientific interest of human beings to understand and manipulate the inheritance of their own characters.

\section{Responses to biotechnology in crop improvement}

The advances in plant transgenics and genomics described above have not been isolated from society (Busch et al. 1991). Some of these achievements have been acclaimed by end-users whereas other accomplishments, e.g. release of genetically modified organisms (GMO), are being attacked, not only in words but also in deeds, by political activists. Some of these educated middle-class campaigners are expressing in this way their rampant 'eco-paranoia', while others hide their real agenda to manipulate the fashionable ecological movement. This controversy has attracted the attention of non-scientific partizans to each side. There have been negative comments about transgenic plants by a crown prince and contrasting positive comments by a former president, both of whom may not have the required technical knowledge to assess the potential of biotechnology for crop improvement. Irrespective of this ideological dispute and ensuing democratic disagreements, biotechnology products will be accepted by people who support scientific-based progress, in a similar way that new cultivars or innovative crop husbandry techniques have previously become integral parts of farming systems elsewhere. However, without end-user's consent, the impact of a new technology in the society will be small or nil.

Scientific honesty seems to the best policy to convince people about the advantages of biotechnology for crop improvement (Frewer et al. 1998). What to do? Scientists, farmers, consumers, and policy-makers should objectively assess the potential hazards of crop biotechnology in farming and food systems regarding the current situation and the likelihood that such hazards may occur. For example scientists should explain to the people that gene recombination (or reassortment) already occurs in nature. However, the ecological success of viable recombinants after gene reassortment is unpredictable owing to the high fitness of current isolates. For this reason, more scientific research will be needed to identify unpredictable risks and the chances of their occurrence.
The need for profit, as in any other business, has attracted the interest of the private sector to defend their investments in crop biotechnology with patents, intellectual property rights, and new protection methods, e.g. 'terminator' technology that inhibits germination of self-pollinated seeds. This technology protection system prevents farmers from saving seeds from their harvest for further utilization as next season planting propagules. Three genes, each with a specific promoter, are inserted into the 'terminator' plant (D.E. Culley, Washington State Univ. in RAFI 1998). One of the genes (e.g. CRE/LOX system from bacteriophages) produces a recombinase that removes a spacer between the gene producing, for example, a ribosomal inhibitor protein and its promoter such as late embryonic abundance, which only becomes active during the late stages of embryo development. This spacer with specific recognition sites blocks the gene (for the ribosomal inhibitor protein) from being activated. Another gene (e.g. tetracycline repressor system) produces a repressor that keeps off the recombinase gene until an outside stimulus is applied to the 'terminator' plant, e.g. a chemical such as the tetracycline, or temperature and osmotic shocks. The United States Department of Agriculture (USDA) and a cotton seed enterprise jointly acquired a patent for this concept (U.S. patent 5,723,765). Two months after this patent was announced, one of the leading agro-chemical transnationals bought the cotton seed company, although one of its officers said that it may take many years before this 'terminator gene' idea becomes a proven technology in the seed industry.

Strategic alliances, joint ventures, research partnerships, new investments, company mergers, cross-ownerships, and take-overs in the seed and agro-chemical business have also been in the news in recent months. Likewise, some leading scientists are leaving their academic appointments to join the new private enterprises in plant biotechnology. These events are happening because the private sector wants to use biotechnology to accelerate its growth in agri-business in the short-term. Nonetheless, funds to support basic and strategic research by public researchers are needed for a long-term sustainable transfer of public goods (both knowledge and technology) to the private sector or other users.

\section{Bioinformatics}

Another important factor in the successes of the genetic improvement of crops was the development of fast and more reliable computers, which allowed easier management and analysis of data as well as publication of scientific reports. The impact of the informatic revolution in crop improvement can be partially assessed by counting the number of publications indexed in Plant Breeding Abstracts (CAB International, Wallingford, Oxon, UK). There was ca. 22-fold increase of publications in the 1930-1997 period (Fig. 1). It was in the 1970s that indexed publications in plant breeding exceeded 10,000 per year. More publications and easy means for retrieving this information accounted 
for such growth of knowledge dissemination in plant genetics and breeding. Today, rapid information exchange has been facilitated with electronic mail and access to the internet to read electronic publications such as this journal. Nowadays, information technology and DNA science are beginning to fuse into a single operation. Computers are deciphering, and organizing the huge genetic information that may become "the raw resource of the emerging biotech economy" in the next century (Rifkin 1998). Scientists working in the new field of "bioinformatics" are developing biological data banks to download the genetic information accumulated during millions of years of life evolution, and perhaps reconstruct some of the living organisms of the natural world.

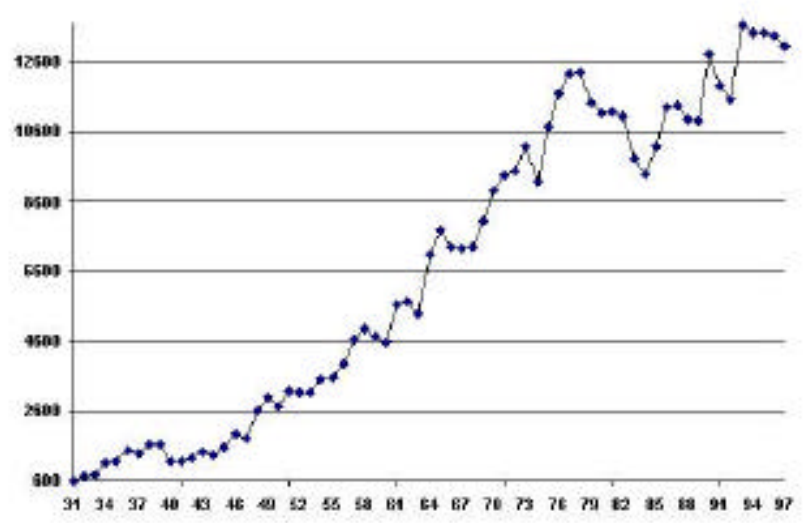

Figure 1. Number of publications indexed in Plant Breeding Abstracts (CAB International, Wallingford, Oxon, UK) since its publication in early 1930 s

\section{Plant genomics}

This new term, defined by the development of biotechnology, refers to the investigations of whole genomes by integrating genetics with informatics and automated systems. Genomic research aims to elucidate the structure, function and evolution of past and present genomes (Liu 1997). Some of the most dynamic fields concerning agriculture are the sequencing of plant genomes, comparative mapping across species with genetic markers, and objective assisted breeding after identifying candidate genes or chromosome regions for further manipulations. As a result of genomics, the concept of gene pools has been enlarged to include transgenes and native exotic gene pools that are becoming available through comparative analysis of plant biological repertoires (Lee 1998). Understanding the biological traits of one species may enhance the ability to achieve high productivity or better product quality in another organism.

DNA markers and gene sequencing provides quantitative means to determine the extent of genetic diversity and to establish objective phylogenetic relationships among organisms. 'Gene chips' and transposon tagging will provide new dimensions for investigating gene expression.
Molecular biologists will study not only individual genes but how circuits of interacting genes in different pathways control the spectrum of genetic diversity in any crop species. For example, more information will be available on why plant resistance genes are clustered together, or what candidate genes should be considered when manipulating quantitative trait loci (QTL) for crop improvement (Paterson 1997).

\section{Farming in environmentally friendly systems}

The aims of applied plant science research for agriculture are to enhance crop yields, improve food quality, and preserve the environment where human beings and other organisms live. The best way for conservation of plant biodiversity and its environment, would be to achieve high crop productivity per unit area. In this regard, Briggs (1998) reported that as yields treble, soil erosion per ton of food decreases by two-thirds. There has been a significant yield improvement owing to enhanced crop husbandry, but in the next years progress will be achieved by changing plants that could be more suitable to sustainable and environmentally friendly farming systems. Agro-chemical corporations are developing pest and disease resistant transgenic crops to avoid pollution with pesticides in the farming system. Furthermore, food quality will become more important than crop productivity in a wealthy society. Consumers will prefer transgenic crops if they have the desired characteristics.

In the next decades meiotic-based breeding will still generate cultivars for farmers. Genetic improvement through biotechnology needs conventional breeding because (1) the elite cultivars will be the parents of the next generation of improved genotypes, (2) field testing across locations or cropping systems and over years will be needed to determine the best selections due to the genotype-byenvironment interaction (Kang and Gauch 1996). As stated by Briggs (1998), "transgenes must be viewed as improvements rather than replacements for elite germplasm". Indeed, genetic engineering may provide a means to add value by introducing synthetic or natural genes that enhance crop quality and yield, as well as protect the plant against pest and diseases. Farmers will pay more for transgenic crop propagules if they obtain extra-income after adopting biotech-derived products. For example, seeds of insect resistant transgenic crops will be more expensive than those of available cultivars but the farmer will not need to apply pesticides in their transgenic fields. Of course, patents make transgenic seeds more expensive but also farmer's benefits may be higher.

\section{Gene banks, DNA banking and virtual plant breeding}

The sequencing of crop genomes opened new frontiers in conservation of plant biodiversity and its genetic enhancement. The advances in gene isolation and sequencing in many plant species allows to envisage that 
within a few years, gene-bank curators may replace their large cold stores of seeds with crop DNA sequences that will be electronically stored. The characterization of plant genomes will ultimately create a true gene bank, which should possess a large and accessible gene inventory of today's non-characterized crop gene pools. Of course, seed banks of comprehensively investigated stocks should remain because geneticists and plant breeders, the main users of gene banks, will need this germplasm for their work. Genomics may accelerate the utilization of candidate genes available at these gene banks through transformation without barriers across plant species or other living kingdoms. Nonetheless, genetic engineering should be seen as one of the methods of plant breeding that permits the direct alteration and re-building of a crop population. "Shutting-off" genes coding for undesired characteristics may be another application of transgenics in crop improvement.

Plant breeders will change their modus operandi with the development of objective marker-assisted introgression and selection methods. Backcross breeding will be shortened by eliminating undesired chromosome segments (also known as linkage drags) of the donor parent or selecting for more chromosome regions of the recurrent parent. Parents of elite crosses may be chosen based on a combination of DNA markers and phenotypic assessment in a selection index, such as best linear unbiased predictors (Bernardo 1998). To achieve success in these endeavours, cheap, easy, decentralized, and rapid diagnostic marker procedures are required.

There are many areas of basic and strategic research in plant breeding and genetics that are being facilitated by marker-aided analysis (Paterson 1996). With molecular markers, plant biologists are reviewing crop evolution and gathering new knowledge. Such information should be incorporated into genetic enhancement programmes, especially those with an evolutionary breeding scheme. Likewise, plant ideotypes for each crop should drive the work of plant breeders. Specific plant morphotypes have been defined in rice and wheat based on accumulated knowledge of crop physiology and crop protection. The needed characteristics required to develop improved plant prototypes ensuing from such a 'virtual breeding' approach may be available in gene banks of the crop or in those of other species. Otherwise, breeders may obtain novel transgenes to develop the required ideotype.

Nowadays, the finding of new genes that add value to agricultural products seems to be very important in the private agri-business. Unique gene databases are being assembled by the industry with the massive amount of data generated by genomics research. A new term 'biosource' was coined recently to refer to a fast and effective licensed technology of pinpointing genes. With this method, a 'benign' virus infects a plant with a specific gene that allows researchers to observe directly its phenotype. Biosource replaces the standard time-consuming approach of first mapping a gene to subsequently determine its exact function. Gene identification in DNA libraries coupled with biosource technology and an enhanced ability to put genes into plants will be routine for improving crops in the next decade.

Genomics may provide a means for the elucidation of important functions that are essential for crop adaptedness (Wallace and Yan 1998). Regions of the world should be mapped by combining data of geographical information systems, crop performance, and genome characterization in each environment. In this way, plant breeders can develop new cultivars with the appropriate genes that improve fitness of the promising selections. Fine-tuning plant responses to distinct environments may enhance crop productivity. Development of cultivars with a wide range of adaptation will allow farming in marginal lands. Likewise, research advances in gene regulation, especially those processses concerning plant development patterns, will help breeders to fit genotypes in specific environments. Photoperiod insensitivity, flowering initiation, vernalization, cold acclimation, heat tolerance, host response to parasites and predators, are some of the characteristics in which advanced knowledge may be acquired by combining molecular biology, plant physiology and anatomy, crop protection, and genomics. Multidisciplinary co-operation among researchers will provide the required holistic approach to facilitate research progress in these subjects.

\section{Pharming and Farmer-ceuticals}

Growth of cities in the developed world has already replaced farmland with shopping malls, parking lots, and housing developments. Peri-urban agriculture and home gardening are also becoming very important for national food security in the developing world as a result of rapid urban expansion. Hence, new cultivars will be needed to fit into intensive production systems, which may provide the food required to satisfy urban world demands of the next century. Specific plant architecture, tolerance to urban pollution, efficient nutrient uptake, and crop acclimatization to new substrates for growing are, among others, the plant characteristics required for this kind of agriculture. Genes controlling these characteristics may be available in gene banks for further cross breeding, which can be assisted by genomics. Peri-urban and home garden "farmers" will have to adapt to new demands from emerging urban populations with higher income. These consumers may request a more varied diet. For example, food crops with low fats, and high in specific amino acids may be needed to satisfy people who wish to change their eating habits. If genes controlling these characteristics do not exist in a specific crop pool they may be incorporated into the breeding pool using transgenics.

Some publications anticipated that in the next millennium food will not need to be harvested from farmer's fields (Anderson 1996b). Tissue culture of certain parts of the 
plant may provide a means to achieve success in this endeavour. For example, edible portions of fruit crops could be grown in vitro. A steady and cheap supply of these edible plant parts will be required in this new agri-business. It will take some time before such a process can be scaledup for commercial output. Nonetheless, a patent was submitted in 1991 by a Californian biotech company for producing a vanilla extract through cell culture. Of course, this technique will not replace farming as we know it today. This biotechnique, as well as other new farming methods, offers a means for new ways of producing food, feed or fibre.

Often plants provide the raw materials for agro-industry, and not only for food or fibre processing. Active ingredients of plants have been transformed into commercial products such as medicines, solvents, dyes, and non-cooking oils for many years. Hence, it would not be surprising to see, in few years from now, entire farms without food crops but growing transgenic plants to produce new products, e.g. edible plastic from peas or plant oils to manufacture hydraulic fluids and nylon (Grace 1997). This new rural activity may result in important changes in the national economic sector.

'Pharming' has been added to the dictionary to indicate a new kind of system to obtain medicines (Anderson 1996b). For example, oral vaccines appear to be a convenient delivery system for vaccination throughout the world. Biotechnology has been used to engineer plants that contain a gene derived from a human pathogen (Tacker et al. 1998). An antigenic protein encoded by this foreign DNA can accumulate in the resultant plant tissues. Results from preclinical trials showed that antigenic proteins harvested from transgenic plants were able to keep the immunogenic properties if purified. These antigenic proteins caused the production of specific antibodies in injected mice. Mice, which ate these transgenic plant tissues, also showed also a mucosal immune response. Arakawa et al. (1998) recently demonstrated the ability of transgenic food crops to induce protective immunity in mice against a bacterial enterotoxin such as cholera toxin B subunit pentamer with affinity for $\mathrm{G}_{\mathrm{MI}^{-}}$ganglioside. Also, potato tubers have been used successfully as a biofactory for high-level output of a recombinant single chain antibody (Artsaenko et al. 1998).

\section{Risk assessment of transgenic crops}

Lack of scientific data, non-scientific partizan views, uncertainty of potential risks, and ignorance confound rational discussion concerning the release of GMO. The issue of releasing genetically modified plants (GMP) into the farming system has become particularly agitated by lobbyist groups in Europe despite widespread cultivation of such crops in North America and elsewhere. Scientists must realise that the general public are concerned that an uncautious approach to the manipulation and cultivation of transgenic crops may affect biodiversity and its sustainable utilization in the farming system, e.g. loss of variability and viability. People also want that their views about applications of biotechnology for improving agriculture are listened irrespective of their knowledge in the subject. Moreover, farmers are afraid that negative propaganda jeopardizes the public image of their products. Scientists and policy markers should not forget that people's acceptability is the most important component of the general public assessment of risk, which includes both uncertainty and negative consequences. This acceptability depends on cultural factors because people's views change according to time and location.

The process of risk assessment in agro-chemical consists of (i) hazard identification, (ii) exposure assessment, (iii) effect's management, (iv) risk characterization, and (v) risk management. However, transgenic crops may be able to invade (or colonize) and multiply in many habitats. Hence, this risk assessment of a genetically modified living organism (also known as GMLO) must consider other characteristics not included when assessing the release of non-living compounds to the environment, e.g. horizontal gene transfer between transgenic crops and wild related species. Scientific risk assessment of transgenic crops must be strictly performed and precautionary principles should be considered in the decision making process. In the industrialized world, this precautionary principle is a key component of the response to the unforeseen (and sometimes irreversible) human and environmental impact, which may occur by introducing into the system new advances ensuing from research and technology development. In Norway, an unique legislation advocates that "the production and use of GMO should be ethically and socially justifiable in accordance with the principle of sustainable development" as well as "safe to humans and to the environment". By applying this framework, marketing applications of GMO could be rejected if insufficient documentation regarding ecological and heath aspects was submitted by the producer.

What are the potential ecological risks associated with the release of GMP into the farming system? These are of course a very large number of potential risks, However, perhaps the two most important risks are:

(i) GMP establishes in semi- or natural habitats, and

(ii) inserted transgenes incorporate into other species, thereby affecting non-target organisms in farms or natural habitats.

Hierarchical test protocols have been proposed to assess the risks of releasing GMP. Such protocols require knowledge about evolutionary history, morphology, life-history characteristics, pollination or breeding system, genetransfer likelihood, natural hybridization, recruitment and vegetative propagation of a chosen species. Likewise, producers should provide, to facilitate this risk assessment, additional information regarding biochemical, physiological, and morphological changes owing to inserted gene(s), along with a list and description of marker and reporter genes included in the transgenic plant. It would also be important to add details concerning when and in 
which plant tissues or organs will be expressed the modified function or phenotype. Nonetheless, people must also know that scientists assessing risks of transgenic crops may extrapolate the outcome or results from simple shorttime experiments into complex long-term natural- or farming systems. Investigations about gene flow and competing ability of transgenic crops may be easily addressed through short-term experiments. However, the assessment of the environmental impact of GMP requires a long-term, expensive, holistic research. Computer modelling, which integrates knowledge about gene flow, competing ability, spread of transgenes to weedy species, and cultural practices in the farming system, may provide an alternative means for long-term risk assessment of releasing GMP into the environment.

Consumer concern about transgenic crops also focuses on their safety as food, especially if modifications could influence their metabolism or health. In this regard, transgenic plants without selectable markers, such as antibiotic resistance genes, are needed to convince GMPsceptics of the advantages of genetic engineering for crop improvement. In this way, their criticism concerning the potential risks of transgenic crops could be overcome. For example, molecular or metabolic markers may provide a means to identify transgenic plants with desired trait(s). Of course, these alternative markers should be safe from an environmental and health perspective.

\section{Outlook}

Within the next 10 or 20 years, five research areas may become very important for crop improvement: (i) apomixis to fix hybrid vigour, (ii) male sterility systems with transgenics for hybrid seed in self-pollinating crops, (iii) parthenocarpy for seedless vegetables and fruit trees, (iv) short-cycling for rapid improvement of forest and fruit trees, and (v) converting annual into perennial crops for sustainable agricultural systems. The development of perennial crops will be especially important to protect the soil from erosion. Plant biotechnology will play, of course, an important role in achieving research and development success in these areas.

Banning transgenic crops in the farming system will be foolish because the potential benefits are so great. Environmentalists should recall or re-read 'Silent Spring' by Rachel Carlson (1962). Whatever scientists do to develop crops that eliminate or reduce the utilization of polluting agro-chemicals in the farming systems must be welcome by farmers and consumers. For example, one interesting approach for developing resistant transgenic crops may be through the improvement of the plant's own defence system. Inducible and tissue specific promoters could assist in this endeavour.

Collective approval may lead to new partnerships, cooperation or joint ventures in research and development between scientists in the public and private sectors that will benefit farmers and consumers with profits and high quality products, respectively. Any potential risk in human development associated with biotechnology applications in agriculture will be easily resolved in a democratic society. The public need to choose between being safely selfregulated or to follow safety regulations as agreed by lawmakers after listening to the views of scientists, producers, and consumers.

The general public should see biotechnology as a safe tool for scientific crop improvement, because it helps in the fight against hunger and poverty. Therefore, research funding should be allocated accordingly to long-term plant breeding programmes, which include biotechnology as one of its tools. In this way, we may effectively face the serious challenge of feeding the rapidly growing world population in the next millennium.

\section{Acknowledgments}

Thanks to the Nordic Council of Ministers for providing funding support to the author via a Nordic Professorship in Plant Genetic Resources, and to Drs. Jonathan H. Crouch (Elsoms Seeds Ltd., Spalding, Lincolnshire, England) and Lise Nørrind Hansen (formerly at KVL, Denmark) for comments during the development of this paper.

\section{References}

Altman, D.W. and Watanabe, K.N. (1995).Plant biotechnology transfer to developing countries. Academic Press, Inc., California and London.

Anderson, J. (1996a). Feeding a hungrier world. Phytopathology News 30 6: 90-91.

Anderson, W.T. (1996b). Evolution isn't what is used to be. W.H. Freeman and Company, New York. 223 pp.

Arakawa, T., Chong, K.X. and Langridge, W.H.R. (1998). Efficacy of a food plant-based oral cholera toxin B subunit vaccine. Nature Biotechnology 16: 292-297.

Artsaenko, O., Kettig, B., Fiedler, U., Conrad, U. and Düring, K. (1998). Potato tubers as a biofactory for recombinant antibodies. Molecular Breeding 4: 313-319.

Bernardo, R. (1998). A model for marker-assisted selection among single crosses with multiple genetic markers. Theoretical Applied Genetics 97: 473-478.

Bourlag, N.E. (1997). Feeding a world of 10 billion people: the miracle ahead. Plant Tissue Culture and Biotechnology 3: 119-127.

Briggs, S.P. (1998). Plant genomics: more than food for thought. Proceedings of the National Academy of Sciences USA 95: 1986-1988.

Busch, L., Lacy, W.B., Burkhardt, J. and Lacy R.L. (1991). Plants, power, and profit: social, economic, and ethical consequences of the new biotechnologies. Basil Blackwell Inc., Cambridge, Massachussetts. 275 pp. 
Ortiz, R.

Carlson, R. (1962). Silent spring. Houghton Mifflin Co., Boston.

Chee, M., Yang, R., Hubbell, E., Berno, A., Huang, X.C., Stern, D., Winkler, J., Lockhart, D.J., Morris, M.S. and Fodor, S.P.A. (1996). Accessing genetic information with high-density DNA arrays. Science 274: 610-614.

Daily, G., Dasgupta, P., Bolin, B., Crosson, P., du Guerny, P., Ehrlich, P., Folke, C., Jansson, A.M., Jansson, B.-O., Kautsky, N., Kinzig, A., Levin, S., Mler, K.G., PinstrupAndersen, P., Siniscalco, D. and Walker, B. (1998). Global food supply: food production, population growth, and the environment. Science 281: 1291-1292.

Erbisch, F.H. and Maredia, K.M. (eds.) (1998). Intellectual property rights in agricultural biotechnology. Biotechnology in Agriculture 20. CAB International, Wallingford. $240 \mathrm{pp}$.

FAO (Food and Agricultural Organization of the United Nations). (1995). Dimensions of need: an atlas of food and agriculture. FAO, Rome, Italy.

Frewer L.J., Howard C. and Shepherd, R. (1998). The influence of initial attitudes on responses to communication about genetic engineering in food production. Agriculture and Human Values 15: 15-30.

Grace, E.S. (1997). Biotechnology unzipped: promises \& realities. Joseph Henry Press, Washington D.C. 248 pp.

Herdt, R.W. (1998). Assisting developing countries toward food self-reliance. Proceedings of the National Academy of Sciences USA 95: 1989-1992.

Ives, C. and Bedford B. (eds.) (1998). Agricultural biotechnology in international development. Biotechnology in Agriculture 21. CAB International, Wallingford. 368 pp.

Kang, M.S. and Gauch Jr., H.G. (eds.) (1996). Genotypeby-environment interaction. CRC Press, Inc., Boca Raton. $416 \mathrm{pp}$.

Kendall, H.W., Beachy, R., Eisner, T., Gould, F., Herdt, R., Raven, P.H., Schell, J.S. and Swaminathan, M.S. (1997). Bioengineering of crops: report of the World Bank panel on transgenic crops. Environmentally and Socially Sustainable Development Studies and Monographs Series 23. The World Bank, Washington D.C. 30 pp.

Lee, M. (1998). Genome projects and gene pools: New germplasm for plant breeding? Proceedings of the National Academy of Sciences USA 95: 2001-2004.

Lemieux, B., Aharoni, A. and Schena, M. (1998). Overview of DNA chip technology. Molecular Breeding 4: 277-289.
Liu, B.L. (1997). Statistical genomics: linkage, mapping, and QTL analysis. CRC Press, Boca Raton. 611 pp.

Marshall, A. and Hodgson, J. (1998). DNA chips: an array of possibilities. Nature biotechnology 16:27-31.

Moore, S.D. (1998). Agrochemical rivalry heats up: AHPMonsanto pact raises pressure. The Wall Street Journal Europe, 5-6 June 1998, p. 10

NCGR.

(1998).

http://www.ncgr.org/gpi/oddysey/agbio/foods.html

Paterson, A.H. (ed.) (1996). Genome mapping in plants. Academic Press, Inc. and R.G. Landes Co., New York and Austin. 330 pp.

Paterson, A.H. (ed.) (1997) Molecular dissection of complex traits. CRC Press, Inc., Boca Raton and New York. 305 pp.

Perkins, J.H. (1997). Geopolitics and the green revolution. Oxford University Press, New York. 337 pp.

RAFI (Rural Advancement Foundation International) (1998) RAFI Communique March/April 1998: How does the terminator technology work? pp. 4-5.

Ramsay, G. (1998). DNA chips: state of the art. Nature Biotechnology 16:40-44.

Rifkin, J. (1998). The biotech century. Victor Gollancz, London. 272 pp.

Simmonds, N.W. (1997). Pie in the sky. Tropical Agriculture Association June 1997: 1-5.

Tacker, C.O., Mason, H.S., Losonsky, G., Clements, J.D., Levine, M.M. and Arntzen, C.J. (1998). Immunogenecity in humans of a recombinant bacterial antigen delivered in a transgenic potato. Nature Medicine 4: 607-609.

Troyer, A.F. (1996). Breeding widely adapted, popular maize hybrids. Euphytica 92: 163-174.

USDA-APHIS (United States Department of Agriculture Animal and Plant Health Inspection Service). (1997). Biotechnology permits database. http://www.aphis.usda.gov:80/bbep/bp/

Wallace, D.H. and Yan, W. (1998). Plant breeding and whole-system crop phyisiology: improving adaptation, maturity, and yield. CAB International, Wallingford, Oxon. $390 \mathrm{pp}$. 